\title{
Reappraisal of the human ocular growth curve in fetal life, infancy, and early childhood
}

\author{
Hans C Fledelius, Anders C Christensen
}

\begin{abstract}
Aims-The aim of this study was to find an algorithm of better fit for early eye growth than the linear regressions usually advanced.

Methods-The analysis is based on previously published around term data, the main material being axial ultrasound measurements in preterm $(n=101)$ and full term infants $(n=25)$. The postconceptional age of the infants ranged between 36 and 54 weeks. Previously published Danish data from eyes of aborted fetuses were also used, as were averaged values from the literature regarding eye size at age 1 year $(20 \mathrm{~mm}), 3$ years $(22 \mathrm{~mm})$, and a presumed 13 year endpoint of $23 \mathrm{~mm}$.

Results-A second order exponential function fitted with the basic data within a standard deviation of $2 \%$.

Conclusions-A simple symbolic expression and tabulated values for eye growth in infancy and childhood were derived. This is clearly of practical value, for example, when following the development of eyes treated for congenital glaucoma or assessing other developmental anomalies and early eye diseases.

(Br f Ophthalmol 1996;80:918-921)
\end{abstract}

By and large the growth of the eye follows the growth pattern of the brain.1 The earlier in life, the greater the absolute and relative increase; about two thirds of the postnatal ocular axial length increase takes place within the first 24-30 months of life; after that age growth further decelerates. The time for attaining final eye size is still under debate..$^{2-4}$

Our knowledge about ocular growth before delivery is based on data obtained from various sources and of varying quality. Classically, the drawbacks of anatomical data derived from abortions are associated with fixation (postmortem shrinkage, etc). ${ }^{5}$ Eye measurement in the live fetus is possible both theoretically and practically by transabdominal ultrasound, but the method has poor resolution and has not been developed beyond pioneering level. ${ }^{6}$

At present the best basis for analysis appears to be ophthalmic axial ultrasound oculometry studies performed via the corneal surface in live infants delivered significantly before term. However, reservations can be advanced: (1) unrest (for example, when crying) in small babies makes measurement difficult; many measuring sets have to be discarded because of poor reproducibility. (2) Eye growth itself could be influenced by the premature birth; this was suggested in previous research based on ex-prematures and controls evaluated oculometrically at the age of 10 years, and again at 18 years. $^{78}$

In 1992-3 two biometric investigations of preterm infants were published, ${ }^{19}$ and after completing the present analysis an extended study of a similar approach appeared. ${ }^{10}$ In all three, in an attempt to derive normative values for the prenatal and perinatal period, averaged growth rates and linear regression analyses were presented.

Presupposing limitations of linear regression as a mathematical model in the present context we have re-evaluated the early part of the ocular growth curve. In this study Danish data from previous investigations are used with the aim of establishing an algorithm for early eye growth.

\section{Material and methods}

In addition to the curve eventually arrived at, Figure 1 shows the axial length values initially selected for the calculation as dependent variable. On the primary axis, age in weeks is given from zero (= start of pregnancy) via 40 weeks (normal delivery) and to the age of 3 years. The three value sets of lowest age are derived from Ehlers $e t$ al $^{5}$ (cadaver eyes), and the following four from in vivo ultrasound measurements (Sonometrics 400, $10 \mathrm{MHz}$ focused contact A-scan biometry transducer, with proper adjustment for the various intraocular sound velocities). ${ }^{1112}$ Authoritative measurement data for early childhood being sparse, the last two datasets were entered as averaged choices as based on several authors. $^{413}$

In cadaver eyes, the inclusion of posterior eye wall thickness tends to skew the axial size

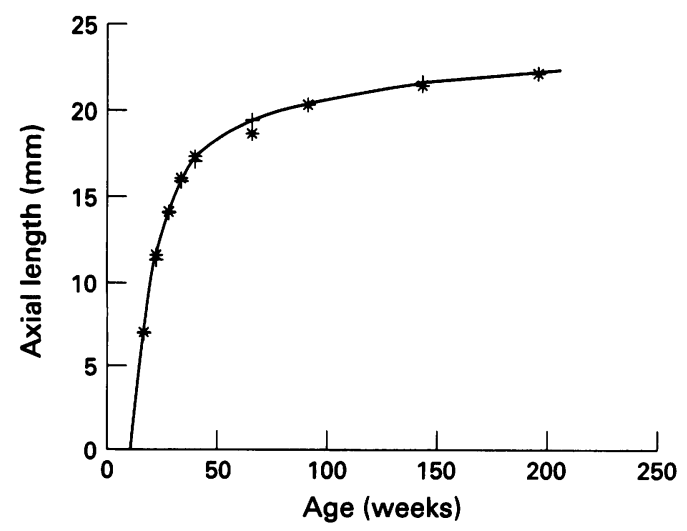

Figure 1 The nine sets of data (asterisks) used as basis for calculation, with the resulting growth curve shown (pluses and line) (see text). Week $40=$ term; week $200=$ about the age of 3 years (post-term). 
estimates towards values which are too high compared with ultrasound measurements. On the other hand, some degree of shrinkage of the globe due to fixation is commonplace in postmortem specimens. ${ }^{5}$ For such reasons an uncertainty due to the measurement method of up to $1 \mathrm{~mm}$ was allowed for every data set.

In order to approximate the observed ocular growth data it has proved advantageous to use a second order exponential function, assuming two relative growth decay rates relevant for before and after term, respectively.

The following function showed a good fit (Fig 1):

$$
\begin{aligned}
f(t) & =f\left(t, K, t_{0}, k_{1}, k_{2}, T_{1}, T_{2}\right) \\
& =K\left[k_{1}\left(1-e^{-\frac{t-t_{0}}{T_{1}}}\right)+k_{2}\left(1-e^{\left.-\frac{t-t_{0}}{T_{2}}\right)}\right]\right. \\
& =K\left[1-k_{1} e^{-\frac{t-t_{0}}{T_{1}}}-k_{2} e^{-\frac{t-t_{0}}{T_{2}}}\right]
\end{aligned}
$$

with the values

$$
\begin{aligned}
& K=23 \mathrm{~mm} ; \\
& k_{1}=0.73 ; k_{2}=0.27 \\
& T_{1}=12 \text { weeks; } T_{2}=100 \text { weeks } \\
& t_{0}=10 \text { weeks }
\end{aligned}
$$

Here $K$ is the value of the function for $t$ going towards infinity. The actual value of $23 \mathrm{~mm}$ is the presumed axial measure at the age of 13 years, the endpoint of eye growth according to Sorsby and Leary ${ }^{2} . T_{1}$ and $T_{2}$ are time constants related to the exponential growth decay rates (12 weeks and 100 weeks, respectively). Before birth a time constant of 12 weeks was used for the growth decay rate, while after delivery a time constant of 100 weeks was considered relevant. Using a first order function instead, with the assumption of only one growth decay rate, the fit was not satisfactory considering the given uncertainty on measurements. $k_{1}(0.73)$ and $k_{2}(0.27)$ are empirically chosen numerical weights approached to best fit (constants with no direct physical interpretation). As a starting point for eye growth, arbitrarily the fetal age of 10 weeks $\left(t_{0}\right)$ was chosen.

The actual relative standard deviation of the data from the above function being only $1.6 \%$ implies a maximum 'worst case' error of 0.35 $\mathrm{mm}$. The most deviating case might have been exchanged with a value set of better fit, but we abstained from 'cosmetic' actions.

\section{Results}

The axial length growth rate $G R$ is obtainable from the above expression for axial length by simple differentiation. This is easily computable by inserting $t$ (age in weeks).

$$
\mathrm{GR}=\frac{d f(t)}{d t}
$$

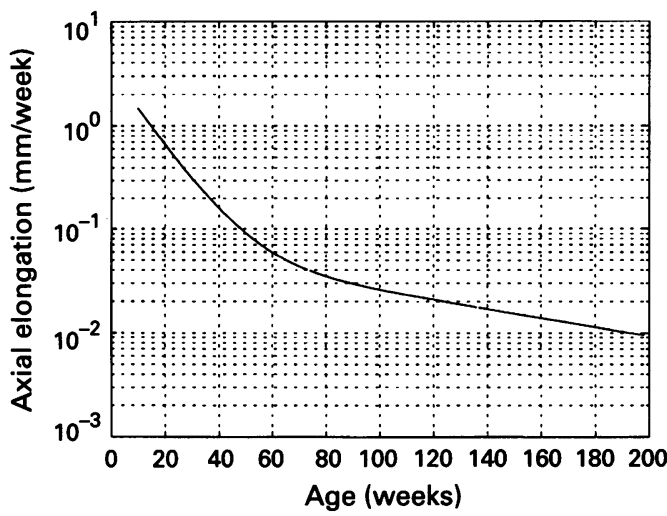

Figure 2 Semilogarithmic presentation of the axial eye growth according to age. The two growth decay rates are suggested as straight line asymptotes.

$$
\begin{aligned}
& =-K\left[\frac{k_{1}}{T_{1}} e^{-\frac{t-t_{0}}{T_{1}}}+\frac{k_{2}}{T_{2}} e^{-\frac{t-t}{T_{2}}}\right] \\
& =-1.40 e^{-\frac{t-10}{12}}-0.062 e^{-\frac{t-10}{100}}\left[\frac{\mathrm{mm}}{\text { week }}\right]
\end{aligned}
$$

Figures 2 and 3 give the growth rate in $\mathrm{mm} /$ week; in the former as a semilogarithmic plot, in Figure 3 directly.

Finally, Table 1 gives growth rates according to the established algorithm at selected values for age, from mid pregnancy past delivery (= week 40) and up to the age of 3 years.

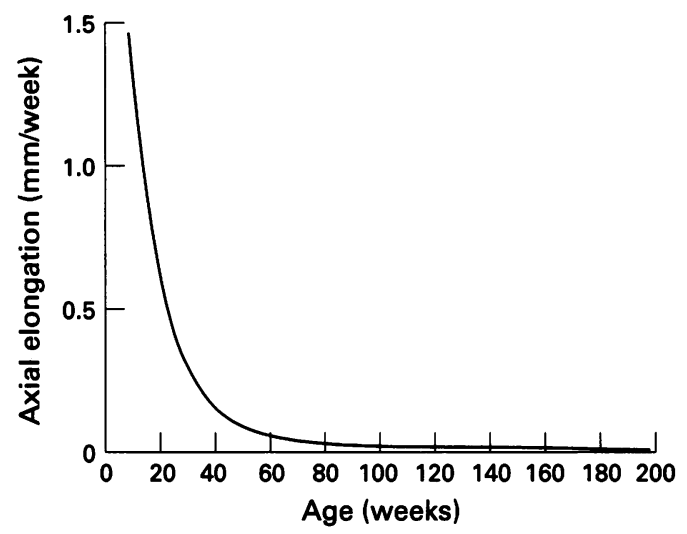

Figure 3 Growth rate as derived from the estimated function.

Table 1 Numerical presentation of ocular axial length according to the present formula, and axial growth rate, from fetal age 20 weeks to the age of 3 years

\begin{tabular}{lll}
\hline Age (weeks)* & $\begin{array}{l}\text { Axial length } \\
(\mathrm{mm})\end{array}$ & $\begin{array}{l}\text { Growth rate } \\
(\mathrm{mm} / \text { week })\end{array}$ \\
\hline 20 & 10.08 & 0.66 \\
30 & 14.74 & 0.32 \\
40 (term) & 17.02 & 0.16 \\
50 & 18.24 & 0.092 \\
60 & 18.97 & 0.059 \\
70 & 19.48 & 0.044 \\
80 & 19.87 & 0.035 \\
90 (about 1 year) & 20.19 & 0.030 \\
100 & 20.47 & 0.026 \\
120 & 20.93 & 0.021 \\
140 (about 2 years) & 21.31 & 0.017 \\
170 & 21.75 & 0.013 \\
200 (about 3 years) & 22.07 & 0.009 \\
\hline
\end{tabular}

$\star<40$ weeks $=$ fetal; $>40$ weeks $=$ post-term. 


\section{Discussion}

ANATOMICAL STUDIES

Classic reviews of prenatal ocular growth ${ }^{5}$ were anatomical - that is, based on weight and size of the eye and its compartments in aborted fetuses.

Ehlers and coworkers devoted much energy investigating and discussing the influence of the various fixation processes actually in use for such material. ${ }^{5}$ Their postmortem data were derived from 107 fetuses aged from menstrual age 10 weeks and up to normal delivery time. Throughout the prenatal period the weight of the eyeball followed the body. After birth, however, the growth of the eye became less rapid.

Considering axial length (and also corneal diameter) the authors found an almost linear increase in the fetal age period. ${ }^{5} \mathrm{~A}$ slightly curved form of the growth curve was, however, suggested for eyeball diameter, and reference was made to Scammon and Armstrong ${ }^{14}$ who suggested empirical exponential functions.

\section{ULTRASOUND STUDIES}

Employing atraumatic ultrasound methods for ocular measurement it has become possible to evaluate size and eye segment proportions from soon after delivery. Concerning the period of life before normal term we have to rely on, and extrapolate from, measurements performed in babies of preterm delivery. Broadly supporting the concept of a 'cerebral' growth pattern, reference is made to reviews compiling available data about the early ocular growth phase $\mathrm{e}^{413}$ and to oculometry reports in the literature. ${ }^{11} 121516$

In 1992-3 supplementary material was published by Tucker et al ${ }^{9}$ and by Denis et al. ${ }^{1}$ Examining the newborn preterm infant in the incubator on day 0-9 Tucker et al declared the aim of establishing normative values for corneal diameter, axial eye length, and intraocular pressure. Valid axial eye length measurements were obtained from 23 subjects aged 25-29 weeks, from 16 aged 30-33 weeks, and from 31 infants in the 34-37 week age group. The mathematical examination used linear regression for the full sample, without attempting a breakdown according to age. The overall axial length increase was $1 \mathrm{~mm} / 23$ days, or $0.3 \mathrm{~mm} /$ week. Extrapolating to 40 weeks' gestation, the authors found fair agreement with established newborn ultrasound term figures. ${ }^{1317}$

Investigating aborted fetuses, Denis et al ${ }^{1}$ likewise attemped to present normative values for various growth factors including eye size and head circumference. Excluding macerated fetuses and malformation syndromes, the abortions included were all considered 'normal'. They were examined within 24 hours after abortion. The eye measurements were performed by ultrasound A-scan. Possibly an influence has been exerted by the lack of circulation and metabolism, by evaporation after death, autolytic processes, etc, on for instance tissue 'tonus' and sound velocity. This study might have been useful in evaluating further how the postmortem ultrasound measure- ments (with the retinal surface as endpoint) had compared with classic caliper measurements. The authors depicted their axial length findings (range $5.7-16.2 \mathrm{~mm}$ ) according to gestational age (range 17-41 weeks) as a regression line with a slope of $0.33 \mathrm{~mm}$ axial length increase/week.

After concluding the present study an investigation into term and preterm internal and external eye growth was published. ${ }^{10}$ With a mean postconceptional age (PCA) of 36.3 weeks (SD 3.9) an average growth of 0.15 $\mathrm{mm} /$ week was given, and a mean axial length at term of $16.2 \mathrm{~mm}$. It was, however, not clear whether the actual term value was based on full term or on preterm infants measured at PCA 39-41 weeks. For the age range under study (PCA 28.5-48 weeks) regression lines for ocular growth were presented, but in the discussion the authors formally questioned the validity of the linear regression model.

Judging from the ocular growth data otherwise presented in the literature, the overall visual impression from data sets and graphs indeed is non-linear. A decelerating growth is obvious, with axial length eventually approaching the adult end value asymptotically. ${ }^{13}{ }^{18} \mathrm{~A}$ semilogarithmic approach has thus been used, in connection with control of axial length increase in congenital glaucoma patients. ${ }^{19}$

Concerning the fetal stages, a backwards extrapolation of the established postnatal curved form appears likely. ${ }^{1620}$ The same impression was gained from our own data, ${ }^{12}$ but subdividing the material into too narrow age groups in a search for successively decreasing tangent slopes invalidated mathematical handling by way of parametric regression statistics. Accordingly, in our previous study only a rough subdivision with reference to term age (40 weeks) was performed: in the age interval of PCA = gestational week $36-40$ a growth of $0.19 \mathrm{~mm}$ per week was established; above the age of 40 weeks the weekly axial length increase was $0.13 \mathrm{~mm} .^{12}$

For biological reasons rejecting a sharp bend in the growth curve associated with term was one of the reasons for undertaking the present analysis of the early ocular growth curve. Further, it was done with a view to the apparent discrepancy between our own averaged growth rates and the attempted normative prenatal values (of 0.3 or $0.33 \mathrm{~mm}$ axial increase/week, respectively) as quoted above. ${ }^{19}$ Obviously, such figures are relevant for the period only as mean values, and are valid only for a specified portion of the prenatal growth curve (cf Table 1).

Admittedly, our own results may have been biased from several sources. One is the possibility of a dampening influence of preterm delivery per se on subsequent eye growth, ${ }^{8}$ theoretically making the observations less representative compared with intrauterine measuring data at similar gestational ages. Further, our selection of data for analysis may be questioned, but so far we have no reason to make other choices. Clearly, there is a need for new techniques to be developed for safe atraumatic ocular measurements in utero to provide 
more accurate data from which to evaluate eye growth. $^{21}$

Until then we propose the present algorithm for early eye growth, and with Table 1 as an easy guide for evaluating measurements of possible clinical importance (for instance in subjects suffering from congenital glaucoma or various ocular malformations).

This work was presented at the World Federation of Ultrasound in Medicine and Biology Conference in Sapporo, Japan in July 1994.

1 Denis D, Righini M, Scheiner C, Volot F, Boubli L, Dezard $\mathrm{X}$, et al. Ocular growth in the fetus. 1 . Comparative study of axial length and other biometric parameters in the fetus. Ophthalmologica 1993;207:117-24.

2 Sorsby A, Leary GA. A longitudinal study of refraction and its components during growth. Med Res Counc Spec Rep Ser No 309, 1970 (Suppl to Rep No 301 of 1961).

3 Fledelius HC. Ophthalmic changes from age of 10 to 18 , part IV. Acta Ophthalmol (Copenh) 1982;60:403-11.

4 Fledelius HC. Die normalen Abmessungen des Augapfels und ihre Veränderungen mit dem Wachstum. In: Buschmann W, Trier HG, eds. Ophthalmologische Ultraschalldiagnostik, Berlin, Springer; 1989:41-8.

5 Ehlers N, Matthiesen ME, Andersen $\mathrm{H}$. The prenatal growth of the human eye. Acta Ophthalmol (Copenh) 1968; growth of

6 Jeanty P, Dramaix-Wilmet M, van Gansbeke D, Van Regemorter N, Rodesch F. Fetal ocular biometry by ultrasound. Radiology 1982;143:513-6.

7 Fledelius HC. Prematurity and the eye (thesis). Acta Ophthalmol (Copenh) 1976; Suppl 128

8 Fledelius HC. Inhibited growth and development as permanent features of low birth weight. Acta Paediatr Scand 1982; 71:645-50.
9 Tucker SM, Enzenauer RW, Levin AV, Morin JD, Hellman J. Corneal diameter, axial length and intraocular pressure in premature infants. Ophthalmology 1992;99:1297-300.

10 Isenberg JJ, Neumann D, Cheong PYY, Ling YLF, McCall LC, Ziffer AJ. Growth of the internal and external eye in term and preterm infants. Ophthalmology 1995;102: 827-30.

11 Fledelius HC. Eye size of the premature infant around presumed term. In: Sampaolesi $\mathbf{R}$ ed. Ultrasonography in Ophthalmology 12. Dordrecht: Kluwer, 1990:165-72.

12 Fledelius HC. Pre-term delivery and the growth of the eye. An oculometric study of eye size around term-time. Paper first read Sept 1991, WFUMB/SIDUO, Copenhagen. Acta first read Sept 1991, WFUMB (Sulmol (Copenh) (Suppl) 1992;204:10-5.

13 Larsen JS. The sagittal growth of the eye, IV, axial length. Acta Ophthalmol (Copenh) 1971;49:873-86.

14 Scammon RE, Armstrong EL. On the growth of the human eyeball and optic nerve. $\mathcal{f}$ Comp Neurol 1925;38: 165-210

15 Delmarcelle Y, Francois J, Goes F, Collignon-Brach J, Luyckx-Bacus J, Verbraeken H. Biométrie oculaire clinique. Paris: Masson, 1976:269-72.

16 Gordon RA, Donzis PB. Refractive development of the human eye. Arch Ophthalmol 1985;103:785-9.

17 Blomdahl S. Ultrasonic measurements of the eye in the Blomdahl S. Ultrasonic measurements of the eye in the
newborn infant. Acta Ophthalmol (Copenh) 1979;57: 1048-56.

18 Tane S, Kohno J. Ultrasonic biometry of the sagittal growth of eyes in children. In: Hillman JS, Le May MM, eds. Doc Ophthalmol Proc Ser 38 (SIDUO IX). The Hague: Junk, 1983:277-93.

19 Sampaolesi R. Ocular echometry in the diagnosis of congenital glaucoma. In: Thijssen JM, Verbeek AM, eds. Doc Ophthalmol Proc Ser 29. The Hague: Junk, 1981: Doc Oph $177-89$.

20 Grignolo A, Rivara A. Observations biométriques sur l'oeil des enfants nés a terme et des prematures au course de la premiere année. Ann Oculist 1968;8:817-26.

21 Fako L, Nardi M, Passani F, Bartolomei MP, Mazzeo V. Ultrasonic measurement of fetal eyeball diameter. In: Ossoinig KC, ed. Doc Ophthalmol Proc Ser 48 (Siduo X). Dordrecht: Nijhoff/Junk, 1987:93-9. 